Federal Reserve Bank of Minneapolis Research Department

\title{
Technical Notes on Facts and Myths about the Financial Crisis of 2008
}

\author{
Maxim Troshkin* \\ Working Paper 667
}

October 2008

\begin{abstract}
Technical details and specific data sources are provided for "Facts and Myths about the Financial Crisis of 2008" by V.V. Chari, Lawrence Christiano, and Patrick J. Kehoe.

*University of Minnesota and Federal Reserve Bank of Minneapolis. Contact: troshkin@umn.edu. The views expressed herein are those of the authors and not necessarily those of the Federal Reserve Bank of Minneapolis or the Federal Reserve System.
\end{abstract}


These notes are intended to supplement Chari, Christiano, and Kehoe (2008) (henceforth referred to as 'the paper') by providing additional details of where the data are obtained, how the series are constructed where appropriate, and technical caveats of several points made in the paper.

First, we describe general data sources used. Then, we address common features of the figures as well as specific technical details of each figure. Finally, we provides details of the argument in the paper about the way the financial system intermediates funds between households and corporate businesses.

\section{Data}

Data available on October 25, 2008 are used. The two principal data sources are the Federal Reserve Board statistical releases and Bloomberg.

\section{A. The Federal Reserve Board statistical releases}

The Federal Reserve Board statistical releases are publicly available free of charge at http://www.federalreserve.gov/releases/. In particular, three statistical releases are used:

- H.8 is a statistical release of the Federal Reserve Board titled "H.8 (510) Assets and Liabilities of Commercial Banks in the United States". The Federal Reserve obtains these data from 30 of the largest commercial banks and a sample of smaller banks. Details of the sampling methodology are at http://federalreserve.gov/releases/h8/about.htm. Total assets of the banking system consist of Bank Credit, Interbank Loans, Cash Assets, and Other Assets. Bank Credit, in turn, consists of securities held by banks and loans made by banks. Loans made by banks are subdivided into Commercial and Industrial Loans, Real Estate Loans, Consumer Loans, Fed Funds and Re- 
purchase Agreements with Brokers, and other loans. Weekly releases are available at http://www.federalreserve.gov/releases/h8/ and historical data from 1973 are at http://www.federalreserve.gov/releases/h8/data.htm. Historical release version of the data is used.

- Z.1 is another statistical release of the Federal Reserve Board. Its full title is "Z.1 Flow of Funds Accounts of the United States". The current release as of October 25 is used, which is Second Quarter 2008 released on September 18, 2008. It is available at http://www.federalreserve.gov/releases/z1/.

- Commercial Paper is the third statistical release of the Federal Reserve Board that is used. Its current release is available at http://www.federalreserve.gov/releases/cp/ and historical data are available through Data Download Program at http://www.federalreserve.gov/DataDownload/Choose.aspx?rel=CP. Historical release version of the data is used.

The data on quantities are weekly and are seasonally adjusted. The commercial paper rates series are constructed by converting daily data to weekly by taking the average over available rates for a given week. A week is taken to end on Wednesday for consistency with H.8 data; this also means fewer weeks contain no data at all allowing fewer missing data points.

Importantly, the October 10, 2008 release of H.8 contains a footnote that states: "Large domestically chartered commercial banks acquired $\$ 259.2$ billion in assets and liabilities of nonbank institutions in the week ending October 1, 2008." The footnote also provides details on the affected subcategories of assets and liabilities. A footnote in the October 24, 2008 
release of H.8 revises some of the amounts.

Since these acquisitions do not represent new loans or new deposits but rather a reclassification of existing ones, in constructing the series for the figures, these amounts are subtracted from the respective totals reported in the historical release. Thus the following amounts are subtracted (in billions): $\$ 234.7$ from Bank Credit (\$233.7 total per October 10 note and $\$ 1.0$ total revision per October 24 note); $\$ 209.7$ from Loans and Leases per October 10 note; $\$ 1.6$ from Commercial and Industrial loans per October 10 note; $\$ 15.5$ from Consumer loans per October 10 note; $\$ 158.8$ from Deposits $(\$ 159.3$ total per October 10 note less $\$ 0.5$ total revision per October 24 note).

The data affected are for the week ending October 1, 2008 and onward.

\section{B. Bloomberg}

Daily data on corporate indices and rates for treasury securities are provided by Bloomberg: Composite rates are based on baskets of the designated securities. Bloomberg constructs yield curves by industry and rating grade based on composite yields for issues in the given industry or rating category around given maturities. The curves for each rating grade are composites of the curves for all the industries. For instance, the AAA curve is a composite of the "AAA Industrials" and "AAA Finance" curves (1 and 21 on the FMC screen).

\section{Figures}

Figures 1 through 14 have an A version and a B version. The A versions of all figures display data from 2001 onward. The B versions display the same data from 2008 onward on the exact same scale as their corresponding A figures. Figures 8B and 9B also display the 
same data for 2007 .

The B figures (except 8B and 9B) also identify five potentially significant financial events during 2008. The specific dates marked on the B figures are:

- March 14, 2008: Bear Stearns fails;

- September 16, 2008: Lehman Brothers fails;

- September 20, 2008: Bailout plan is proposed;

- September 25, 2008: Washington Mutual fails;

- September 29, 2008: Wachovia is taken over.

Figures 1 through 7 display weekly data; figures 8 and 9 are based on quarterly data; figures 10 through 14 display daily data.

We now provide additional details specific to each figure.

Figures 1A and 1B. The data displayed are Bank Credit given by line 1 on page 1 of H.8 Historical data, adjusted as described in the previous section.

Figures 2A and 2B. The data displayed are Loans and Leases in Bank Credit - a subcategory of Bank Credit - given by line 5 on page 1 of H.8 Historical data, adjusted as described in the previous section.

Figures 3A and 3B. The data displayed are Commercial and Industrial Loans and Leases - a subcategory of Loans and Leases in Bank Credit - given by line 6 on page 1 of H.8 Historical data, adjusted as described in the previous section.

Figures $4 \mathrm{~A}$ and $4 \mathrm{~B}$. The data displayed are Consumer Loans and Leases - a subcategory of Loans and Leases in Bank Credit - given by line 11 on page 1 of H.8 Historical data, adjusted as described in the previous section. 
Figures 5A and 5B. The data displayed are Interbank Loans given by line 18 on page 1 of H.8 Historical data. They are not adjusted in any way.

Figures $6 \mathrm{~A}$ and $6 \mathrm{~B}$. Total amount of outstanding Financial and Nonfinancial Commercial Paper are displayed. The series come from Commercial Paper release with the following unique identifiers: CP/OUTST/DTBSPCKF.WW and CP/OUTST/DTBSPCKN.WW respectively.

Figures 7A and 7B. The rates displayed are for AA Financial, AA Nonfinancial, and A2/P2 Nonfinancial Commercial Paper with 90-day maturity. The source is Commercial Paper release series CP/RATES/RIFSPPFAAD90_N.B, CP/RATES/RIFSPPNA2P2D90_N.B, and CP/RATES/RIFSPPNAAD90_N.B respectively. They are converted to weekly frequencies as described in the previous section.

Figures 8A and 8B. The data displayed are based on Table F.102 in Z.1. "Retained Earning + Dividends" is the sum of lines 3 and 9 of Table F.102. Data codes are FA106120005.Q and FA106000105.Q respectively. Retained Earning are given by line 9, FA106000105.Q. Capital Expenditures are given by line 11, FA105050005.Q.

Figures 9A and 9B. The data displayed are based on Table F.102 in Z.1. Net New Equity Repurchases are the negative of line 39 of Table F.102. The data code for this line is FA103164003.Q. Credit Market Instruments are given by line 40, FA104104005.Q. Net Funds Raised are line 38, FA104102005.Q.

Figures 10A and 10B. The data are three month LIBOR (in U.S. dollars) and Treasury Bill rates from Bloomberg. Bloomberg tickers are "US0003M Curncy" and "usgg3m index" respectively.

Figures 11A and 11B. The data are one month LIBOR (in U.S. dollars) and OIS (in 
U.S. dollars) rates from Bloomberg. Bloomberg tickers are "US0001M Curncy" and "ussoa curncy" respectively.

Figures 12A and 12B. The data are three month BBB Corporates and Treasury Bill rates from Bloomberg. Bloomberg tickers are "c8833m index" and "usgg3m index" respectively.

Figures 13A and 13B. The data are three month AAA Corporates and Treasury Bill rates from Bloomberg. Bloomberg tickers are "c8803m index" and "usgg3m index" respectively.

Figures $14 \mathrm{~A}$ and 14B. The data are one month LIBOR (in U.S. dollars) and Effective Fed Funds Rate rates from Bloomberg. Bloomberg tickers are "US0001M Curncy" and "FEDL01 curncy" respectively.

\section{Bank Lending to Nonfinancial Corporate Businesses}

The data from Z.1 are the basis of the arguments in the section of the paper about the way the financial system intermediates funds between households and corporate businesses.

The details of Figures 9A, 9B, 10A, and 10B are described in the previous section. The claim that about $20 \%$ of nonfinancial corporate debt is held by banks is based on the following calculation.

The total amount of funds that nonfinancial corporate businesses obtain from banks and by issuing publicly traded bonds - that are held by nonbank financial institutions such as life insurance companies as well as directly by households - is calculated as the sum of Corporate Bonds (line 26 in Table L.102 of Z.1) and Bank Loans n.e.c. (line 27 in Table L.102 of Z.1), which amounts to $\$ 4402.2$ billion. 
Bank lending to nonfinancial corporate businesses is estimated as the sum of Bank loans n.e.c. (line 27 in Table L.102 of Z.1) and Corporate and Foreign Bonds assets of commercial banks (line 9 in Table L.109 of Z.1), the latter is prorated according to the fraction of Nonfinancial Corporate Business Bonds (line 3 in Table L.212 of Z.1) in Total Corporate and Foreign Bonds (line 1 in Table L.212 of Z.1). The result is calculated to be $\$ 1034.325$ billion, which is only about $20 \%$ of $\$ 4402.2$ billion.

\section{References}

[1] Chari, V.V., Lawrence Christiano, and Patrick J. Kehoe (2008) "Facts and Myths about the Financial Crisis of 2008", Working Paper 666, October 2008, Federal Reserve Bank of Minneapolis. 